\title{
THE SUCCESSFUL REMOVAL OF BRAIN TUMORS
}

\author{
REPORT OF A SERIES OF EIGHT CASES * \\ WILLIAM G. SPILLER, M.D. \\ AND \\ CHARLES H. FRAZIER, M.D. \\ PHILADELPHIA
}

In presenting for review this series of tumors of the brain, successfully removed, we have selected tumors of various types and various localities as representing different problems in localization and in surgical management. In consideration of the operability of brain tumors, the reports in current literature are frequently misleading. For example, many cases are recorded as brain tumors in which the brain tumor was not seen at operation or verified at necropsy. For practical considerations such reports are of no value as neither the nature of the tumor nor its precise location is specified. It cannot be classified on the basis of its pathology nor with relation to accessibility since its precise location remains undetermined. These two phases of brain tumor, character and location, are the only ones of practical moment when considering the question of operability.

Then, too, in estimating the incidence of operable in contrast with inoperable tumors, the time has come when a classification should be made and adopted as a basis of all discussions. It is quite as improper to include all kinds of tumors of the brain in one group when attempting to evaluate operative possibilities or operative risks as it would be to discuss under one heading all surgical lesions of the stomach. There is as much difference between the sharply defined endothelioma and the subcortical infiltrating glioma as there is between sharply defined gastric ulcer and the diffuse carcinoma. In the stomach the latter represent separate and distinct problems; quite as separate and distinct are the problems presented by various tumor types of the brain.

The following classification might be acceptable.

Pretentorial

(a) Benign Tumors

1. Fibroma

2. Osteoma

3. Enchondroma

4. Tuberculoma

5. Endothelioma

6. Miscellaneous

\footnotetext{
* Read at the Forty-Seventh Annual Meeting of the American Neurological Association, Atlantic City, N. J., June, 1921.
} 
(b) Malignant Tumors

1. Glioma

(a) Cortical, subcortical

(b) Infiltrating, circumscribed.

2. Endothelioma

3. Tuberculoma

4. Miscellaneous

(c) Pituitary Lesions

(d) Miscellaneous

Subtentorial

1. Acoustic Tumors

2. Angle Tumors (Not Acoustic)

3. Hemispheric Growths

(a) Endothelioma

(b) Fibroma

(c) Glioma

(d) Tuberculoma

(d) Miscellaneous

This classification would afford a basis for intelligent discussion and for the comparative studies of reports from various sources. It is manifestly unfair and misleading in considering the question of operative risk to consider tumors of all types together. For example, operations even though only exploratory, in cases of subcortical glioma are always hazardous; and the general mortality of surgical efforts in brain tumor should be reckoned for each of the several groups as proposed in our classification.

Not until, as a class, operations are undertaken at an earlier period will there be any striking change in the incidence of successfully extirpated growths. In a certain number there is an extraordinarily long latent period even though the tumors are not situated in the silent areas of the brain, but in too many instances has there been an unconscionable delay in recognizing tumor probabilities and recommending surgical intervention.

The following cases have been selected as representing tumor types and various locations:

1. An endothelioma of the left occipital lobe

2. A tuberculoma of the parietal lobe near the motor cortex

3. An encapsulated glioma of the motor area

4. A calcified endothelioma of the falx

5. An unusually small endothelioma near the motor cortex

6. A fibroma of the posterior fossa origin undetermined

7. A glioma of the cerebellar hemisphere

8. An acoustic tumor (fibroma). 
Two of these cases have clinical features of unusual interest. Case 2 has been employed for a discussion of epilepsia partialis continua affecting the face, and its relation to convulsive movements of the face from irritation of the facial nerve. Case 5 is of special interest because of the small size of the tumor and the importance of aphasia as a localizing symptom. This was a case in which removal of the tumor effected a complete disappearance of all symptoms, a cure in every sense of the word. There has been so much dispute regarding the importance of Broca's area in motor aphasia that Case 5 with sharply defined attacks of motor aphasia and the discovery and removal of a small endothelioma from or very near Broca's area with complete disappearance of these attacks of aphasia is of importance in the controversy regarding aphasia.

\section{REPORT OF CASES}

CASE 1.-Summary: An endothelioma of the occipital lobe removed from a patient, who continued free from recurrence three and a half years after operation.

History.-M. P., aged 41, was sent to the neurosurgical service of the University Hospital by Dr. R. S. Hooker, as a case of brain tumor. Her previous medical, family and social history contains nothing that bears directly or indirectly on the lesion under consideration.

Four months ago the patient began to complain of frontal headaches, at first observed in the morning, of a few hours' duration. Gradually they increased in severity and continued longer until at the present time they are practically constant. Almost contemporaneous with the headaches dizzy spells developed. These came and went with the headaches. On only one occasion was there complete loss of consciousness and then only for a few moments. With the headaches and dizziness the patient noticed that she was having difficulty in "walking straight" in the dark and more particularly in keeping her equilibrium when going down stairs. Later even in daylight hours she could not walk without staggering. There had never been, so far as she knew, any weakness of either the upper or lower extremities; there had been for several months an aching pain in the legs, especially at night, and edema of the legs coincident with dyspnea and palpitation on exertion. For three months she had been annoyed by vomiting, sometimes once, sometimes three or four times a day, without relation to meals. She thought there had been some diminution in the acuity of her sense of taste, of smell and hearing and some impairment in memory. During the period of her illness she had lost twenty pounds.

Physical Examination.-Cranial Nerves: None of the cranial nerves were involved with the exception of the optic nerve. (See ophthalmic report.)

Motor Function: There was no impairment of movement or strength in either of the upper or lower extremities.

Sensory Function: There was no impairment of any form of sensation, no. paresthesia, no loss of sepse of position or stereognostic perception.

Reflexes: Biceps and triceps reflexes were equal and normal. The right patellar tendon reflex was more prompt and of slightly greater intensity. There was no ankle clonus and no Babinski sign. 
Coordination and Equilibrium: There was no ataxia in the upper extremities. Diadokokinesis was good in both hands. A suspicion of asynergia was aroused by the right finger to nose test. Standing with eyes closed the patient swayed slightly, chiefly to the right.

Ophthalmic Report: The pupils reacted sluggishly to light and accommodation. Vision in the right eye was $6 / 60$; papilledema, plus 5 diopters. Vision in the left eye was $6 / 30$; papilledema, plus 4 diopters. There was right lateral homonymous hemianopsia.

Ear Report: Labyrinths, auditory nerves and brain-stem appeared normal. Bárány tests suggested pressure over the cerebellum of supratentorial growth.

Roentgen-Ray Report: The posterior clinoid processes were somewhat attenuated. The sella turcica was slightly enlarged. There was a possible suprasellar growth. The right internal auditory meatus was larger than the left.

Miscellaneous: The Wassermann reaction of the blood and spinal fluid was negative. The spinal pressure was $32 \mathrm{~mm}$. of mercury, and the spinal fluid contained 10 cells. The urinalysis was negative. Hematolysis: hemoglobin, 60 per cent.; white blood cells 9,900; red blood cells 3,420,000.

Summary of Findings: Headache, nausea, vomiting; right lateral homonymous hemianopsia; papilledema; disturbed equilibrium and doubtful asynergia (right).

Operation.-A craniotomy was performed with total extirpation of the tumor. Ether anesthesia was given, endopharyngeal method, in the face down position. A large cranial flap was reflected to uncover the entire left occipital and in part the left parietal lobe. The dira was found to be under tremendous tension. An attempt at puncture of the posterior horn of the ventricle failed. An attempt to evacuate the ventricle by callosal puncture also failed. Simultaneously an incision was made in the dura and a lumbar puncture performed. On withdrawal of a small amount of fluid excessive pressure was controlled. The tumor presented on the mesial surface of the occipital lobe and extended to the base. Differentiation between the brain tissue and tumor was not difficult, and the tumor was enucleated without difficulty. Encapsulation was complete, and there were no attachments except along the surface of the falx. There was moderate bleeding from the falx; this was readily controlled by hot tampons and muscle grafts. The removal of the tumor left a large cavity bounded by the falx, tentorium cerebelli and occipital lobe. The wound was closed (Fig. 1).

Blood Pressure Observations: During the preliminary steps the systolic pressure was 90 ; on exposure of the tumor the systolic pressure was 80 ; after removal of the tumor the systolic pressure was 70 .

Pathologic Report.-The tumor was well encapsulated and the capsule was intact throughout except at the point of attachment to the falx. The tumor measured $10 \mathrm{~cm}$. in the largest diameter. The histologic diagnosis was endothelioma.

Subsequent History.-The postoperative convalescence was uneventful. The patient was relieved of all her subjective symptoms, her fields now are partially restored, and she is now well and free from recurrence three and a half years after the operation (Figure 1).

Comment.-This case is cited as illustrative of the type of endothelioma growing pretentorial. The rate of growth is invariably slow, 
and there are well authenticated cases in which the history would imply a period of fourteen years' growth. In this series is included a case in which the symptoms were of ten years' duration, and the tumor must have had its origin a number of years before its existence was suspected. It is interesting in the case we are discussing to note that, in a tumor of that size (diameter, $10 \mathrm{~cm}$.) there had been no subjective or objective evidence of its existence more than four months before its removal. The most plausible explanation for this really sudden onset of symptoms is ventricular distention. There is no doubt that at this time the outlet to the ventricles became obstructed, and for the first time signs of excessive intracranial pressure manifested themselves.

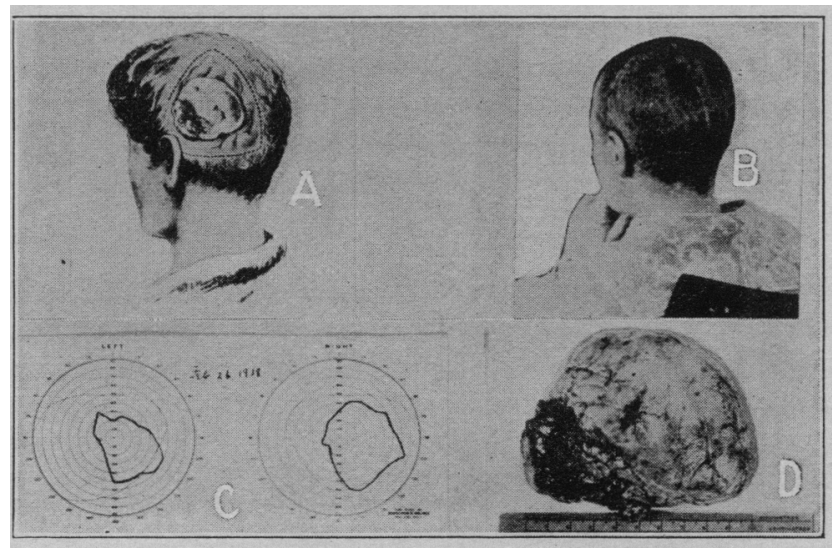

Fig. 1. $-A$, schematic drawing of tumor in situ; $B$, patient two weeks after operation; $C$, right homonymous hemianopsia; $D$, tumor, showing complete encapsulation except at point of origin from falx.

Failure to reach the ventricle on the side of the tumor, either directly or by callosal puncture, would lead one to the conclusion that the ventricle had been compressed and the space practically obliterated by the tumor.

The reason d'etre for some of the symptoms recorded in the history is not clear. Subjectively the patient reported diminution in acuity of sense of taste, of smell and of hearing, but on examination these apparent disturbances were not verified. Taste, smell and hearing were normal.

Had it not been for the homonymous hemianopsia, obviously the characteristic focal symptom, and that at a slightly earlier period the fields were normal, there might have been an error in localization; there was unquestioned evidence of disorder of the right cerebellar hemisphere, the result of the transtentorial pressure of the tumor. It is worthy of note in passing that from the ear clinic the report was 
returned without any explanatory note that the examination suggested pressure on the cerebellum by a supratentorial lesion. In the words of the ophthalmic report, there was a right homonymous hemianopsia. This is not strictly accurate; the charts portrayed what was really a quadrinopsia. Not much more than a quarter of the fields was involved. It has been said that a quadrinopsia is peculiar to lesions of the temporal lobe. Perhaps this may be an exception to the rule.

There is little to be said by way of comment on the purely surgical aspects of this case. With the localization clearly defined to the occipital lobe the tumor was readily uncovered by the reflection of a flap large enough to include all the occipital and a part of the parietal lobe. In all exposures for lesions posterior to the Rolandic fissure, the patient should be in the prone position on the operating table, that is, with face down. Our extension head-rest designed originally for suboccipital operations, meets all the indications for supra-occipital cases. The encapsulation of the endothelioma facilitates the operator in finding the line of cleavage between the tumor and brain tissue. The problem of hemostasis arises only when separation of the tumor from its area of attachment or point of origin on the falx begins. Sharp hemorrhage is then encountered and may be temporarily controlled by tampons of cotton or, if the area be not too large, by direct pressure with the finger. The latter is preferable as it lends itself to the "postagestamp" method of control, which originated during the war, for gunshot wounds of the longitudinal sinus. A piece of muscle or aponeurosis, conveniently taken from the temporal muscle, of proper dimensions, is placed on a finger tip of the free hand and, as the finger of the hand controlling the hemorrhage is withdrawn, the finger with the muscle graft takes its place. When hemorrhage was uncontrolled except with the pressure of a large cotton tampon, the tampon was left in place, the wound closed completely and in the course of three or four days reopened and the tampon removed without recurrent bleeding.

The subsequent course of events is as one would anticipate after a radical removal of a tumor of the endothelioma type. There has been no recurrence or signs of recurrence after a period of over three years. Though of larger dimensions than corresponding tumors of the spinal cord, the surgical possibilities closely parallel one another. The endothelioma of the spinal cord and of the brain when pretentorial is distinctly an operable growth in the technical sense of the word and is one of the most favorable tumors for operation. If not removed entirely, however, it may recur and in the recurrence the tumor is not likely to be well defined. An infiltrating endothelioma is distinctly a malignant growth, it is inoperable and of rapid development. 
The absence of word deafness and word blindness in a tumor of the left occipital lobe is to be explained by the fact that the tumor was on the mesial side of the cerebral hemisphere, and evidently originated from the falx cerebri to which it was attached. It had its origin from a region of the brain in which the only localizing sign to be expected was hemianopsia. An endothelioma grows very slowly and causes atrophy of the brain proportional to the size of the tumor and therefore may not cause symptoms until it has reached a considerable size unless it is situated in a part of the brain functionally active.

CASE 2.-Summary: The removal of an unusually large tuberculoma from the left hemisphere of an adult, male. The operation performed in tzero sittings and a ventriculogram made in the interval; recovery.

History.-U. F., aged 26 years, was referred to the neurosurgical service for operation by Dr. William G. Spiller. There was no history of tuberculosis in the family. The patient had been a noncommissioned officer in the United States army, and had served in France. Before his present illness he was engaged as a hotel porter.

He was perfectly well until nine months before coming under observation. While sitting and talking he said he felt sick and suddenly began to make a grunting noise. His head jerked rapidly back and forth. His eyes were starey, he frothed at the mouth, bit his tongue and voided urine. This attack, in which his legs and arms did not move and he did not fall from the chair, lasted several minutes. He was put on the couch and slept for an hour. For seven months he had similar attacks as often as once a week; he knew when they were coming on and carried a spoon which he put in his mouth so that he would not bite his tongue. Once an attack came on while he was walking to a chair; his head began jerking and, though someone was holding him, there was no tendency to fall. For the past two months the attacks have been mild, and he has not frothed at the mouth or bitten his tongue.

Three months ago he began to have trouble in speaking. He knew what he wanted to say but could not find the word. This irritated him so that he often gave up the attempt to talk. He also stuttered. For the past two months he has been drowsy and continually yawning; he complained of headache which he could not localize; occasionally he has been incontinent both as to bladder and bowel. He has dragged his right foot for some time but not markedly so; he was too weak to lift a chair but could drag it where he wished.

Before his illness he was alert and intelligent and had always done well at work. During the past two months particularly there has been a notable change in his condition.

Physical Examination.-The patient was a well nourished and well developed adult negro. He was stuporous and fell asleep two or three times during the examination. If a question was asked abruptly he answered it, but if followed immediately by a second question there was no response.

Thorax: There was no cardiac enlargement but there was a loud systolic murmur at the apex not transmitted to the axilla. The right side of the chest was slightly more prominent than the left, the sternum inclining to the left. The percussion note was resonant throughout; at the left apex there was prolongation of expiration. There were no râles. 
Cranial Nerves: There was bilateral papilledema plus 4 diopters, of the second cranial nerve. There were many retinal hemorrhages. Third, Fourth and Sixth Nerves: The pupils were equal and reacted sluggishly to light. The ocular movements were full in all directions. There was no nystagmus. Seventh Nerve: He did not draw up the right corner of the mouth as well as the left. Frequent rhythmical twitching was observed confined to the right side of the mouth. Twelfth Nerve: Slight deviation of the tongue to the right when protiuded was noted. Extremities: The grasp of the right hand was weaker than that of the left. In walking he was uncertain and dragged the right foot.

Reflexes: Biceps and triceps tendon reflexes also patellar tendon reflexes, right and left, were not obtained. The Achilles tendon reflex on the left was absent. The Achilles tendon reflex on the right was very weak.

Dr. Spiller reported: The patient is markedly stuporous but can be aroused and can answer questions correctly. During the examination, he has frequen: rythmical twitching confined to the right side of the mouth. This is usually more pronounced when he separates his lips in showing his teeth. He does not draw up the right corner of the mouth as well as the left. It is impossible to test him for hemianopsia because of blindness, but he seems to see the hand in the right fields, but it is impossible to determine this accurately. The tongue deviates a little to the right when protruded. The jerking of the right corner of the mouth is like that of epilepsia partialis continua. He responds to all simple commands and answers in short sentences without any definite aphasic symptoms. He understands all that is said to him, so he is not word deaf. The grasp of the right hand is distinctly weaker than that of the left. The finger to nose test is well performed on both sides. It is impossible to test his sense of position because of his mental condition. In walking he is very uncertain and drags the right foot. I cannot obtain either the patellar reflex or the left Achilles reflex; there is a very weak right Achilles reflex.

Diagnosis: Probably brain tumor of left motor region of cerebrum. It is impossible to localize with accuracy because of the advanced condition of the disorder. The continuous jerking of the right side of his face is suggestive of irritation of the face center of the left motor cortex. It is singular that the right side of the face when the patient is quiet may show no tremor but voluntary movement of mouth, as in showing teeth, at once starts it.

Miscellaneous: The blood contained 4,880,000 red blood cells, 11,800 white blood cells and 90 per cent. hemoglobin. The Wassermann test of the blood was negative. Urinalysis: Specific gravity 1.013 , alkaline reaction, mucus ++ , no red blood cells, from 5 to 10 white blood cells to the field.

Summary of History and Symptoms: History: (1) convulsive seizures for nine months, confined to the head, involving especially the face; (2) aphasia, three months' duration; (3) headache, drowsiness and incontinence for two months, and (4) weakness of the right arm and leg. Symptoms: (1) frequent rhythmical twitching of the right side of the face; (2) weakness of the right side of the face, upper and lower limbs; (3) both patellar and left Achilles reflex absent, right very weak; (4) headache and drowsiness; (5) papilledema, plus 4 diopters bilateral, and (6) pyuria.

Preoperative Diagnosis: Tumor left motor cortex, near face center.

Operation.-A craniotomy was performed by Dr. Frazier and his staff. At the first sitting ether anesthesia was used, endopharyngeal method. A cranial flap was reflected for exposure of the left motor cortex. When the dura was exposed it was found to be under tremendous pressure. Attempts made to 
reduce pressure by ventricular puncture on the left side, both direct and by callosal puncture, failed. As it did not seem wise to open the dura until the pressure could be reduced, an attempt was made through separate opening to evacuate the right ventricle. A few cubic centimeters of blood-stained fluid escaped, but the pressure was not affected. At this point the exploration was discontinued and the wound closed.

Vontriculogram.-One week after the first sitting 100 c. c. of fluid were withdrawn intermittently and 100 c.c. of air injected (10 c.c. of fluid withdrawn and 10 c.c. of air injected). The roentgenogram of the skull did not reveal any air shadow in the ventricle. The latter was obliterated evidently by the tumor.

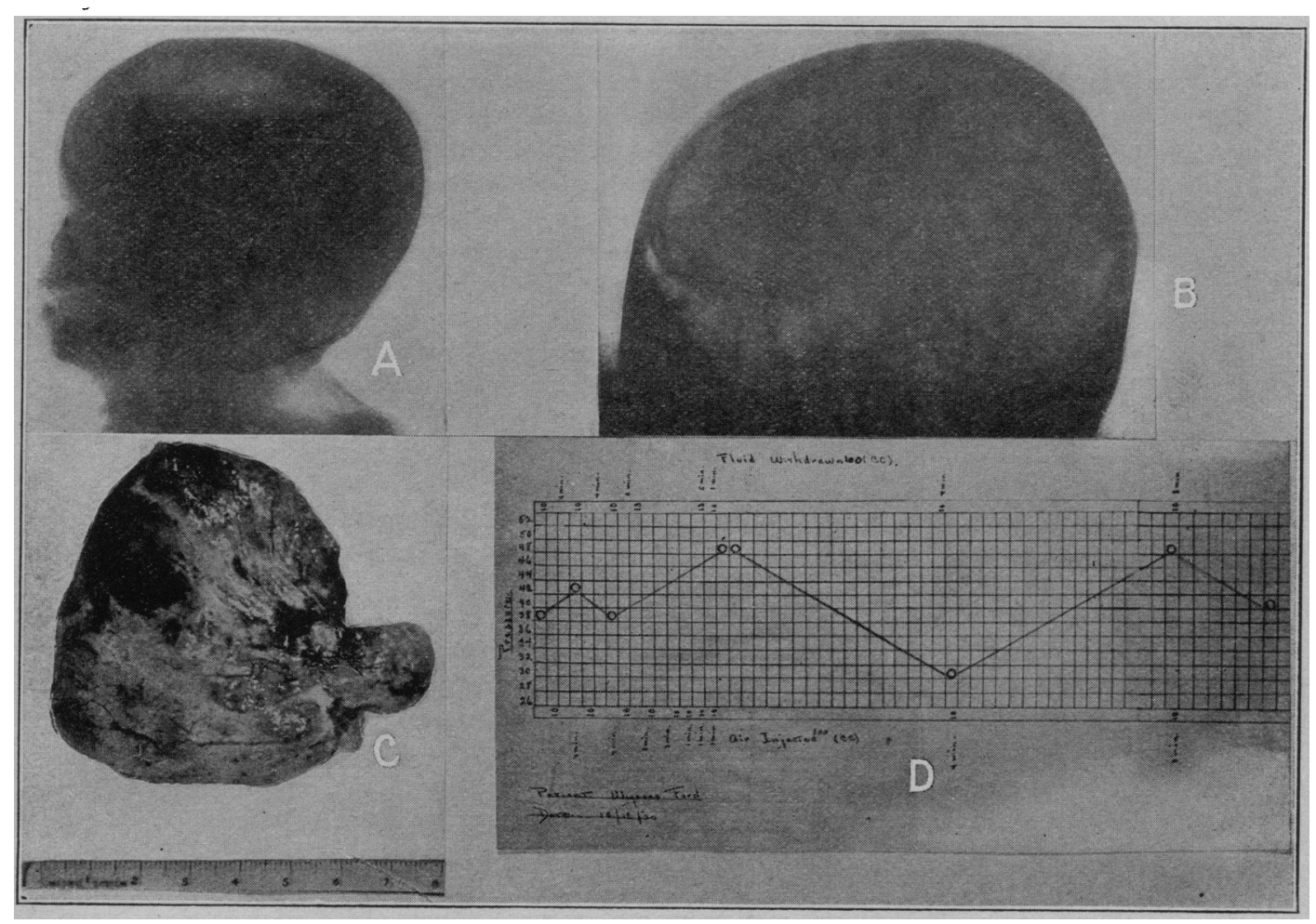

Fig. 2.- $A$, air shadows symmetrical in dilated ventricles of a case of hydrocephalus; $B$, absence of air shadow, ventricles compressed by tumor; $C$, encapsulated tuberculoma which caused collapse of ventricles-photographed immediately after removal; $D$, pressure observations as fuid was withdrawn and air injected.

Exploratory Craniotomy; Second Sitting.-Two weeks after the first sitting and one week after ventriculography exploration was continued. The wound was reopened. The subdural tension was as high as at the first sitting. Lumbar puncture was done with withdrawal of 45 c.c. of cerebrospinal fluid. Immediately tension was restored to normal limits. A dural flap was reflected and the tumor presented at the anterior, inferior quadrant of the opening (near the 
junction of the Rolandic and Sylvian fissures). The tumor was sharply defined from the surrounding tissue, and its isolation and extirpation were readily accomplished. The tumor had no relation with the falx and was moderately adherent to the dura, perhaps had already infiltrated it. Oozing from the tumor cavity was trivial and was readily controlled with hot saline irrigations. The wound was closed. As a precautionary measure, 250 c.c. of citrated blood with 250 c.c. of saline solution were transfused at the conclusion of the operation.

Pathologic Report.-On removal the tumor measured 6 by $8 \mathrm{~cm}$. It was irregular in shape, nodular on the surface and definitely encapsulated, except on a portion of the anterior surface. Pathologic diagnosis: tuberculoma (Spiller).

Postoperative Record.-Immediately after the operation there was a transitory hemiplegia and aphasia. Within a comparatively short time the man could move the arm and leg and could talk. Five days after removal of the tumor an examination of the eyegrounds showed a subsidience of the papilledema from plus 4 diopters to plus 2 to 3 diopters, and the signs of hemorrhages seen before the first operation had entirely disappeared. There was for several weeks an irregular febrile course that could not be accounted for and something seemed to retard the patient's convalescence.

A complete search was made for the primary tuberculous lesion. Dr. Pepper reported that there was no evidence of pulmonary tuberculosis. The urine, however, showed an increased quantity of pus, there was tenderness over the region of the right kidney and muscle rigidity in the upper right quadrant of the abdomen. A provisional diagnosis of pyelitis of the right kidney was made and the patient was transferred to the urological service. The patient died while in this service twenty-two months later.

Comment.-A word might be said about the specimen. It was interesting and unusual from several aspects. Tuberculoma is more common in children, is more frequently found in the cerebellar hem-ispheres, and is not of large dimensions. In all these particulars the tumor did not conform to type. It developed in an adult, in the left cerebral hemisphere and measured over $8 \mathrm{~cm}$. in one of its diametersa large tumor. Tuberculoma of the brain is secondary to tuberculous lesions elsewhere. The original lesion may be latent or, as in this case, unrecognized before the cranial exploration. If the patient had tuberculosis of the kidney it could not have been very active for a long period, since the patient was reported in excellent health up to within nine months of his operation.

The method of exposure and of extirpation departed from the routine in two particulars. The operation was divided into two sittings and in the interim a ventriculogram was made. When uncertain as to the finding of a tumor or "of one's ability to remove it if found, and when the intracranial pressure is extreme, we dislike to reflect the dural flap until at least an attempt is made to relieve the pressure by withdrawal of cerebrospinal fluid. Puncture of the anterior or posterior horn of the ventricle, according to the location of the opening, should be tried. We failed to reach the posterior horn of the right or left ven- 
tricle, either directly or by callosal puncture. Either the approach was misdirected or the ventricles were collapsed. We could have proceeded at once to a lumbar puncture but recognized the incidental risks and decided to determine by ventriculography whether one or both ventricles were distended or collapsed and if distended what their geography was.

After one week's interval the ventriculogram was made and the roentgenogram explained our failure to find the ventricles. The ventricles were collapsed, at least there was no air shadow after 100 c.c. of air had been injected. The preparation for a ventriculogram is not unattended with risk under any conditions and particularly when the intracranial pressure is at a high level. This was realized, but one has to measure and weigh relative values, and a complete survey of the cerebrospinal space seemed desirable before the dura was finally opened. The risks were minimized in preparing for the ventriculogram by withdrawing the fluid intermittently. As from 5 to 10 c.c. of fluid were withdrawn, an equal amount of air was injected. Pressure observations were made frequently with a mercury manometer. Using, as we do, a three way cock, merely by the turning of the handle one may (1) take pressure, (2) withdraw fluid or (3) inject air. By repeated observations on the pressure and fractional withdrawal of fluid we reduced the risks to a minimum. There is an appreciable difference in the risk of fluid withdrawn by lumbar puncture in tumors above and below the tentorium. Below the tentorium we regard it as prohibitive.

Ventriculography is in its infancy; as time goes on we will be able to define with greater accuracy the margin of safety and with the confidence of experience will be able to determine its sphere of limitation. In the case under consideration it served a useful purpose. It was of no assistance in the localization of the growth, but it visualized the condition of the ventricles. Had the ventriculogram been made before the operation, we would have been able to finish at one sitting.

Some might question the propriety of a lumbar puncture at the time of the operation in pretentorial growths, but when simultaneously the presșure is relieved above by the reflection of the dural flap, the conditions responsible for foraminal hernia following lumbar puncture do not prevail.

In intracranial procedures mastery of the problems of pressure is essential to the safe conduct of the case. It is in this aspect of the day's work that judgment and experience count.

The condition was far advanced in this case when the man came under the observation of one of us (Spiller). In addition to the general and focal symptoms of tumor, he had a peculiar constant rhythmical jerking confined to the right side of the mouth, and voluntary innervation increased the jerking, as when he separated his lips in 
showing his teeth; he could not draw up the right corner of the mouth as well as the left. Occasionally, as in the morning after the night's rest, this rhythmical contraction of the muscles of the right side of the mouth was not so conspicuous but became marked immediately when he answered a question. It seemed as though the left facial center were under continual irritation, and voluntary innervation of this center increased its irritability. The condition was that of epilepsia partialis continua, like that described by one of us (Spiller) in association with Dr. Edward Martin. ${ }^{1}$ This case has been referred to by Dr. George Wilson. ${ }^{2}$

In this paper with Dr. Martin one of us (Spiller) was able to give very few references to the literature on epilepsia partialis continua and none to any observations published in English or French. Oppenheim had made a brief mention of it in saying that cases occur in which during the interparoxysmal period muscular twitchings of short duration and without loss of consciousness are observed in one or another part of the body. It had been described by Russian writersKoshewnikow, Muratoff, and Bechterew, and it had been mentioned by Bruns. In the paper by Spiller and Martin emphasis was laid on the fact that the movements differ from those of myoclonic epilepsy in that the twitchings are limited to a small portion of the body and are usually more intense than in myoclonia. Orlowski had reported a case of epilepsia partialis continua and Choroschko had written a monograph on the disorder, but Bruns was the only one not Russian who had observed this rare type. There seemed to be no lesion discovered in any case, so that the case of Spiller and Martin was the first in which a lesion was actually found and the first therefore to establish clearly a cortical origin for the spasmodic movements. In this case jacksonian convulsions occurred, but independently of these typical attacks the man had twitching confined to the right side of the face lasting an indefinite period, an hour or more at a time and occurring very frequently. There were periods in which he had none of these spasmodic movements, but the movements were almost constantly present and resembled a tic movement or fibrillary twitching. They were not excessive in their intensity and implicated the muscles about the right side of the mouth, about the right eye, the right cheek, the right ear and the right side of the neck. After persisting for some weeks in the face they ceased in this part and were observed in the right upper limb. The whole right upper limb was displaced in these clonic movements,

1. Spiller, William G., and Martin, Edward: Epilepsia Partialis Continua Occurring in Cerebral Syphilis, J. A. M. A. 52:1921 (June 12) 1909.

2. Wilson, George: The Diagnostic Significance of Jacksonian Epilepsy, J. A. M. A. 76:842 (March 26) 1921. (Case 1.) 
but the displacement was not excessive, and the spasm consisted of slight twitchings lasting indefinitely as did the previous twitchings of the right side of the face. Dr. Martin operated and small gummas were found in the motor cortex.

A case of epilepsia partialis continua was reported by $\mathrm{Burr}^{3}$ in 1915.

The rhythmical tremor occurring in the present case of tubercle from irritation of the facial center might be confused with the spasmodic jerking resulting from irritation of the facial nerve, as from a tumor of the cerebellopontile angle. In the former condition the contractions are continuous, there is nothing that can be spoken of as an attack; in the latter condition the contractions occur in attacks and simulate the usual epileptiform facial convulsion from irritation of the facial center; indeed convulsive movements have been attributed to irritation in this part, which in reality were caused by irritation of the facial nerve from a tumor. This occurred in a case studied by Dr. Mills with one of us (Spiller) in 1901. Facial spasms were observed in this case under the care of Dr. Mills, and the notes of this case were employed by Weisenburg $^{4}$ in a paper on cerebellar tumors published in 1905 . The facial spasm was unilateral and caused the mouth to be drawn forcibly to the left and the left eyelids to be drawn together. Both observers thought a tumor was probably located in the facial center of the cerebral cortex of the opposite side and operation was performed; later a cerebellopontile tumor was found. At that time the diagnosis of cerebellopontile tumors was not so well understood as it is now, and facial spasms occurring in attacks had never been reported by any one as a result of irritation of the facial nerve from tumor of the cerebellopontile angle. This patient was completely deaf in the ear on the side in which the facial spasms occurred, but four years before coming under observation the ossicles of the ear on this side had been removed on account of annoying tinnitus, but without the desired result.

In Weisenburg's Case 2 the spasms were limited to the entire distribution of the facial nerve, these coming on without any warning, being first tonic in character and lasting from half a minute to a minute. The lesion was not found. In another case reported by him in which a tumor was found in the right cerebellopontile angle the upper. branch of the seventh nerve had been cut, and there had been some

3. Burr: Am. J. M. Sc. 149: No. 2, 1915.

4. Weisenburg, T. H.: Diagnosis of Tumors and Other Lesions in the Cerebellopontile Angle, J. A. M. A. 50:1251 (April 18) 1908; Cerebellopontile Tumor Diagnosed for Six Years as Tic Douloureux, ibid. 54:1600 (May 14) 1910. New York M. J. Feb. 11 and 18, 1905. 
return of power in the distribution of this branch. The man had involuntary twitchings in the middle and lower facial distribution; these were sometimes fibrillary, sometimes coarse and spasmodic and were caused by pressure on the seventh nerve. Spasms of the tongue, apparently chiefly right-sided, were observed in this case.

In a patient studied by one of us (Spiller) in 1915 convulsive movements occurred in the left side of the face lasting only a few minutes. A tumor was found in the cerebellopontile angle, and a similar case has been observed recently.

Cushing ${ }^{5}$ reported before this Association in 1916 two cases of facial spasm caused by peripheral irritation of the facial nerve from a tumor of the cerebellopontile angle. One of these cases is described in detail. It had been previously diagnosed as a case of focal epilepsy from a lesion of the contralateral cerebral cortex. He states that in a series of about fifty tumors in this angle this irritation symptom in a corresponding degree had not been observed. He refers to a paper by Stewart and Holmes in which it was said that evidence of direct irritation of the facial nerve rarely occurs though twitching may occasionally be observed. Cushing. describes the spasm in one of his cases as a twitching of one side of the face beginning as a blepharospasm of mild degree coming on a few times a day and lasting for a few seconds. The attacks gradually increased in number, intensity and surface extent until the spasmodic movements became very severe, coming on every ten minutes or so and persisting for a full minute or two. They began with a twitching and drawing of the muscles about the eye, and gradually the whole side of the face was pulled over in a grimace and the surface muscles of the neck (platysma) were affected. The patient stated that in a few severe attacks the left arm and leg mildly participated in the attack and that the left arm and hand felt numb on several occasions, but this Cushing thought was an erroneous statement. The facial spasms were precipitated by talking, laughing or excitement. The man had no control over the spasms and no weakness of the facial nerve supply. The spasms had existed for nine or ten years. A cerebellopontile tumor was found at operation. As the man lived, the cerebral cortex was not examined, but the facial spasms gradually subsided after the operation.

There may be difficulty in diagnosing between the convulsive movements produced by irritation of the facial nerve and those from irritation of the cortical center for the face, as in epilepsia partialis continua. The careful study of the case will usually permit the correct diagnosis, especially the association with other symptoms. In the form from corti-

5. Cushing, H.: Convulsive Spasm of Face, J. Nerv. \& Ment. Dis. 44:312 (Oct.) 1916. 
cal irritation the twitching is likely to be confined to the lower part of the face, as in Pönitz's case to which reference is made further in this paper, whereas in the form from irritation of the facial nerve the whole distribution of the facial nerve is likely to be affected from the beginning. The differential diagnosis may, however, be complicated.

The facial nerve may be irritated to produce convulsive movements of the face without any paralysis of the facial distribution, as in Cushing's case and one observed by one of us (Spiller), or there may be a statement, possibly erroneous, of convulsive movements in muscles outside of the facial distribution; this leads to confusion. It seems singular that convulsive movements of the face from irritation of the facial nerve occur relatively seldom, and yet the number of cases of tumor of the cerebellopontile angle is considerable.

CASE 3.-Summary: Accurate localization and successful extirpation of an encapsulated glioma from the left cerebral hemisphere; recovery.

History.-R. McK, aged 30 years, was referred to the neurosurgical service at the University Hospital by Dr. T. P. Farmer of Syracuse, New York, who realized the possibility of a brain tumor, an opinion subsequently confirmed by operation. The patient had had the usual diseases of childhood, including scarlet fever, and appendicitis and catarrhal jaundice; otherwise his health had been good. He had been married two years; his wife and one child, aged 16 months, were well. He denied venereal disease.

Eighteen months prior to admission the patient had a convulsive attack while asleep. It was noted that during the attack he lay on his face moaning "with the left foot out of bed shaking." In two weeks he had another attack, this one during the day. He lost consciousness and foamed at the mouth. Two weeks later he had another attack, and during the first twelve months he had twelve convulsive seizures. During the past six months the seizures had been more frequent, two or three a day, but of quite a different character. In these he did not lose consciousness; the convulsions always began in the fingers of the right hand; the fist was clenched and the arm abducted to a right angle with the body. The muscles of the right side of the neck were involved in the tonic spasm. He had never bitten his tongue, nor had there been any involuntary evacuation. With the exception of these attacks, he felt perfectly well.

After admission to the hospital, the convulsions continued; there was in rapid succession flexion of the fingers, wrist and elbow. The arm was then raised to a right angle with the body, and the muscles of the neck participated in the clonic spasm. Consciousness was preserved.

Physical Examination.-Thorax: There was slight impairment on percussion at the left apex; inspiration was slightly prolonged and harsh. The area of cardiac dulness was normal; there were no cardiac murmus.

Cranial Nerves: There was no impairment of function.

Motor Function: In all movements the right forearm and right arm were distinctly weaker than the left; there was no difference in strength of movement between the right and left lower extremities.

Sensory Function: This was unimpaired. 
Reflexes: The biceps and triceps tendon reflexes were exaggerated on the right side; the patella tendon reflexes were equal and normal. There was no ankle clonus and no Babinski sign.

Coordination and equilibrium were undisturbed.

Ophthalmic Report: The pupils were equal and regular in outline and reacted. equally to light and accommodation. There were no ocular palsies and no nystagmus. The fields were not contracted and there was no papilledema.

Miscellaneous: The Wassermann, globulin and colloidal gold tests of the spinal fluid were negative. There were 8 cells per centimeter. The Wassermann reaction of the blood was negative, hemoglobin 81 per cent. and the white blood cells numbered 7,900 . The roentgenogram was negative.

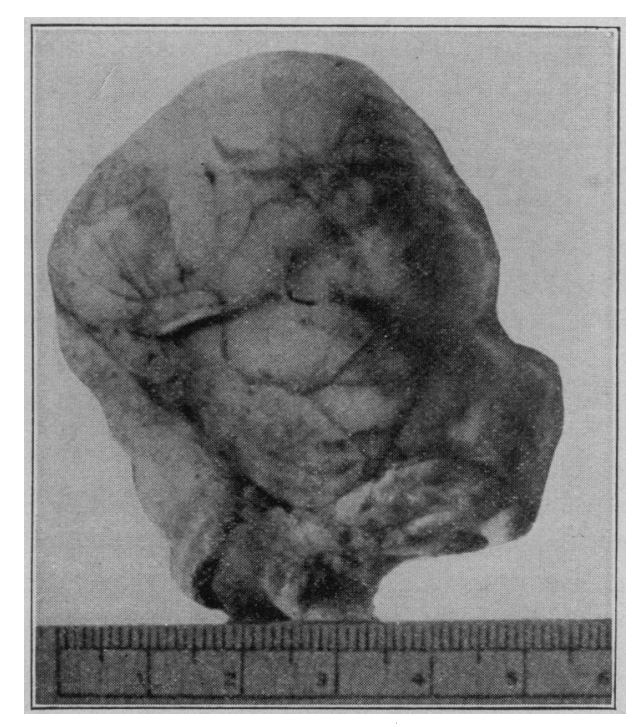

Fig. 3.-Encapsulated glioma.

Summary of Physical Findings: The findings were (1) initial convulsive seizures general in character; (2) later substitution of these with typical jacksonian seizures (right) ; (3) weakness of the right arm, and (4) exaggerated biceps and triceps tendon reflexes (right).

Preoperative Diagnosis: Tumor motor cortex (left).

Operation.-Dr. Frazier and staff performed an exploratory craniotomy. Ether anesthesia was used and a flap was reflected for exposure of the left motor cortex, two-thirds in front and one-third behind the Rolandic fissure. As soon as the cortex was exposed the lesion was seen in the upper half of the field, in front of the Rolandic fissure. Closer examination revealed a sharp line of demarcation between the tumor and the brain tissue. Around the margins of the tumor as exposed the pial vessels were ligated and with gentle dissection the tumor was freed from the surrounding tissue and removed. The tumor extended $5 \mathrm{~cm}$. below the surface and inward as far as the median line. Its point of origin was undetermined, although at the operation we suspected the 
falx. Following the removal of the tumor bleeding was trivial; there were but three bleeding points in the tumor bed and these were. controlled with muscle grafts. The tumor measured 5 by $6 \mathrm{~cm}$. The wound was closed without drainage.

- Pathologic Diagnosis.-Grossly the tumor resembles an endothelioma but histologically it is a glioma, apparently well defined, but not entirely so (Dr. W. G. Spiller).

Postoperative Course.-Immediately after the operation the patient had aphasia and hemiplegia. Within a week, however, he began to recover from both and eventually fully recovered his power of speech and the power of the right leg. The movements of the right arm were still impaired and the limb somewhat spastic. When the patient was examined within a year of the operation, he had had four convulsive seizures; the first two occurred a few months after the operation and were jacksonian in type. There was twitching of the right side of the face and a burning, throbbing sensation in the right arm. In the first convulsion he lost consciousness, in the second he did not.

The second two convulsions occurred nine months after the operation. While talking, speech suddenly failed him, he felt a tense drawing feeling in the right arm and leg, the right arm was abducted and the right leg extended. $\mathrm{He}$ remained unconscious for ten minutes. Immediately after he went to bed and within a few moments, a second convulsion, similar to the first, occurred.

Nine months after the operation speech was undisturbed and the power of the leg was restored, but the arm continued weak and spastic. The eyegrounds were normal.

Comment.-The facility with which tumors may be localized when originating in or over the motor cortex is a point in their favor from the standpoint of operability. One might presuppose that in the majority of cases an early diagnosis would be established when the tumor was in its incipiency. Such is not always the case, however. In two of the cases in this series, Case 2 and Case 3, the tumors were of large dimensions and the duration of the symptoms only eighteen months in one and nine months in the other. The origin of these tumors, as to time, is, of course, a matter of conjecture, but as a rule tumors of the brain are slow in growth and one might presuppose with reason a growth $6 \mathrm{~cm}$. or more in diameter might have been several years in process of development.

The history of the convulsions in this case is interesting. For the first twelve of eighteen months prior to the operation they were general in character with loss of consciousness but without focal signs; in the last six months conditions were reversed; consciousness was preserved and the convulsions were typically jacksonian. One can readily account for jacksonian seizures in a lesion pressing on or actually infiltrating the cells of the motor cortex; but in the absence of signs or evidence of increased pressure, without distention of the ventricles, one wonders why the incipient convulsions should have been general and attended with lost consciousness, unless they were caused by general increase of 
intracranial pressure before the motor cortex of one side was irritated by the tumor.

As in many pretentorial growths, there were no pressure signs; neither headache nor papilledema. This implies of course that the outlet to the ventricles had not been closed and as yet there was no internal hydrocephalus, the most common cause both of headache and papilledema in tumors of the brain without regard to location.

The pathology of this tumor is of unusual interest. In his report Spiller referred to the growth as having the gross appearances of an endothelioma, and so it appeared to the operator. But the histologic examination revealed a glioma, so that we were dealing with a definitely encapsulated glioma, a lesion quite unique in the experience of our clinic. Not only were we deceived in the naked eye appearance of the growth, but as well in our assumption that it had its origin in the falx. With regard to encapsulation of gliomas, of course one often sees what appears to be a distinct wall surrounding a cyst of gliomatous origin. But in this case there was no cyst, and in all the gliomas hitherto exposed in our clinic there have been ill defined margins as the infiltrating tumor invaded the surrounding tissue. We have never seen a definite encapsulation such as in the specimen under consideration. There was, to be sure, a small area on the surface of the growth without a capsule, but we are disposed to believe that in removal this portion of the capsule had become detached.

The postoperative complications, aphasia and hemiplegia, did not disturb us at first. The trauma and edema incidental to the removal of the brain tumors often cause transitory interruption of function. In so far as the aphasia and leg were concerned, the recovery of function in both was no exception to the general rule. The persistent weakness and spasticity of the arm imply, however, irreparable injury.

Whether the convulsions subsequent to the operation were caused by a recurrence or by cerebral trauma is still an open question; either of course would explain them; but one would hardly expect a recurrent growth within five months of the operation, the date of the first convulsion, to be of sufficient size to be responsible for them. We can, with just as much reason, attribute the convulsion to the immediate effects of the operation trauma, hemorrhage and cicatrization. In all patients with epileptic seizures we give luminal, $1 \frac{1}{2}$ grain, in the evening, from the day of the operation for a period of six months to a year or longer.

CASE 4.-Summary: A calcified endothelioma intrahemispheric, exposed at operation and treated by radium implantation zerith relief from convulsions and headaches.

6. While this tumor was not removed, this case is included in the series because of the relief which followed the exposure of the tumor and direct radium implantation. 
History.-O. T., aged 37 years, was admitted to the neurosurgical service of the University Hospital, April 11, 1920, referred by Dr. M. H. Tallman. She had had measles and chickenpox in childhood and diphtheria at the age of 20 . She had had two miscarriages, one before and one after the birth of a living child (now $3 \frac{1}{2}$ years old). A maternal aunt had epilepsy. Otherwise her family history was negative. She was married five years ago. She was engaged in housework and her living conditions were wholesome.

Ten years before admission the patient first complained of momentary attacks of dizziness, occurring about seven times a day. Three months after the onset of these she noticed that during an attack the left knee became weak and she nearly fell. These attacks continued for four months, at the end of which time she had her first severe convulsion. The convulsions were preceded by a choking

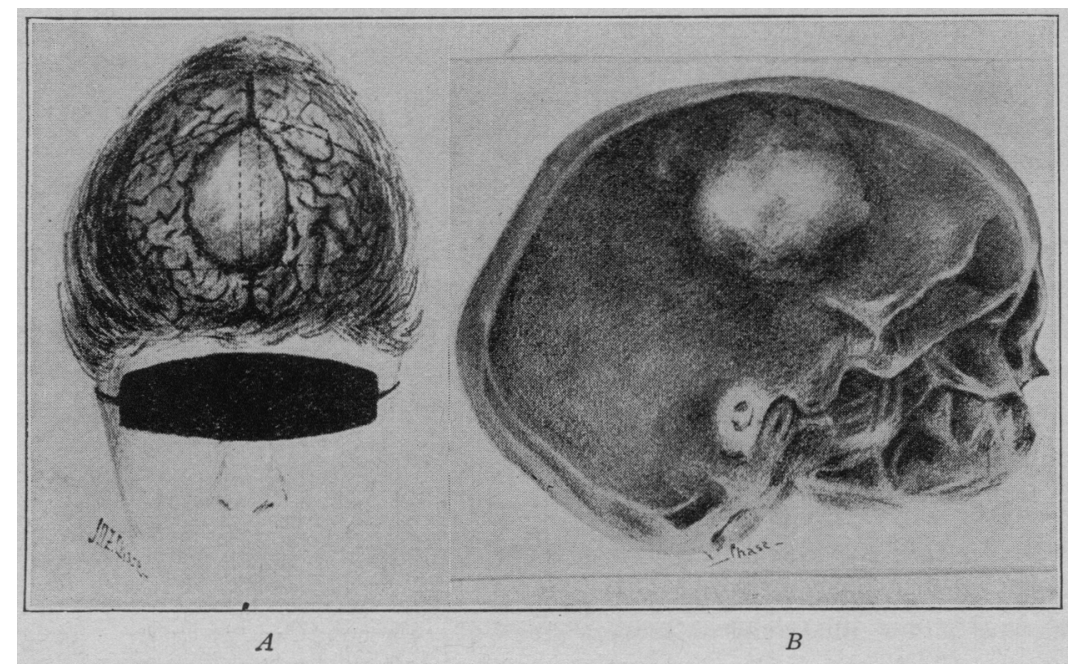

Fig. 4. $-A$, schematic drawing showing relation of tumor to longitudinal sinus; $B$, drawing of roentgenogram showing calcification of tumor.

sensation, the left arm was abducted, the lower left limb drawn up, and she lost consciousness for about ten minutes. She came out of the convulsions groaning, but did not fall asleep. Only the left side of the body was involved in the convulsions. At first they occurred about once a month, then gradually they became less frequent and after her first child was born there was an interim of a year and nine months in which she had no attacks at all. About two months before admission the attacks recurred, lasting a few minutes; in these attacks her left upper and lower limb felt numb, and she could not raise her left arm or foot. During this period for the first time she complained of blinding headaches, occurring about once a week, sometimes in the right temporal region and sometimes in both.

Physical Examination.-Examination of the scalp, nares, teeth and tonsils was negative. The post-cervical glands were palpable. The lungs were normal. There was a systolic murmur over the aortic area of the heart. Blood pressure was: systolic 100 ; diastolic, 70. Examination of the abdomen was negative. Urinalysis: The specific gravity was 1.024 . The urine was acid and there was a 
trace of albumin. There was no impairment of motion in either arm or leg, and normal sensation was preserved. Both the right and left patellar reflexes were exaggerated.

The Wassermann test of the blood and spinal fluid was negative.

Eye Examination.-Muscular movements were free and equal. The pupils were equal and regular and reacted to light and accommodation. Right eye: The media were clear and the disk margins were veiled with fine striations running out into the retina. The veins were overful and slightly tortuous. There were no discrete lesions of the choroid or retina. Left eye: The media were clear and the disk margins obscured. The disk was elevated from 1 to 2 diopters. The veins were full and tortuous. There were no discrete lesions of the choroid or retina.

Roentgen-Ray Examination.-This showed a calcified tumor, extending from the vertex more than half way to the base of the skull. It was viewed anteroposteriorly, in the midline position, extending more to the right than to the left. There was no evidence of intracranial tension and no sellar deformation.

Preliminary Diagnosis: Calicified endothelioma.

Exploratory Craniotomy.-First Stage: Flaps were reflected on both right and left sides, uncovering the region of the tumor and the longitudinal sinus. The patient's condition was not tolerant. No attempt was made to remove the tumor at this sitting.

Second Stage: Nine days later the flaps were again reflected and the tumor exposed. The situation of the tumor with relation to the longitudinal sinus made it evident that a section of the sinus would have to be removed with the tumor. Furthermore, the tumor had infiltrated the overlying dura so that to extirpate the tumor successfully would require removal en bloc of the tumor, overlying dura and a portion of the longitudinal sinus. A dural incision circumventing the tumor was made. The longitudinal sinus, anterior to the tumor, was divided and closed with silk ligatures. Though there had been little bleeding and a minimum of trauma, the patient's condition gave us concern. The pulse rate was 150 and of poor quality. No further steps at extirpation were taken for the moment. Exploring with the finger the tumor was found to be attached to the falx and to extend almost (if not to) the base of the skull. So firm were its attachments that there was no play either in the lateral or anteroposterior directions. On account of the patient's condition and because the tumor was so firmly attached, further attempts at removal seemed too hazardous. The dural and scalp incisions were closed. Direct transfusion was made of 500 c.c. of citrated blood.

Radium Implantation.-May 14, 1920, eighteen days after operation, under procain anesthesia, a small area of skull overlying the tumor was removed with rongeur forceps. A container with radium, $50 \mathrm{mg}$., was implanted in the tumor. In attempting to direct the container toward the center of the tumor, it was obstructed by some impermeable substance (calcified areas in the tumor). The container had to be directed forward to imbed it completely in the tumor. The radium was removed in eighteen hours. The dosage was $900 \mathrm{mg}$. hours.

Postoperative Record.-Immediately after this exploratory craniotomy the patient developed a hemiplegia from which she had largely recovered at the time of her discharge. Thirteen months after the operation, her physician 
wrote that the patient was feeling very well, that while she had attacks of dizziness once in a while, she had had none of the convulsive seizures since her discharge. In response to a suggestion that she return for a second radium treatment, the patient stated that in view of her improvement, she did not feel justified in incurring the expense of the journey across the continent from her home in the West to the hospital.

Comment.-There are many points of interest in this case. For almost ten years the history of the growth was characterized solely by unilateral convulsive seizures involving the left arm and the left leg. The fact that after the seizures the patient experienced weakness in the arm and leg had aroused a suspicion of tumor. It was not until well within the tenth year of her illness that other focal signs developed, such as transitory periods of numbness in the left arm and left leg and, for the first time, blinding headaches. In spite of the duration of the lesion and of its huge proportions, in spite of the blinding headaches, there was little evidence of increased intracranial pressure in the condition of the optic disks. It is noted in the eye examination that there was an elevation of only from 1 to 2 diopters in either disk.

Had there been any doubt as to the diagnosis, and there could have been little, the evidence of the roentgenogram was conclusive. From the shadow of the tumor in the roentgenogram one is justified in making a preliminary diagnosis of calcified endothelioma, although in another case, a tumor quite as vividly revealed in the roentgenogram proved to be an enchondroma.

The location of the tumor, practically intrahemispheric and beneath the longitudinal sinus, necessitated a two flap operation, one reflected to the left and one to the right. This two flap operation I found gave a splendid approach and exposure. The immobility of the tumor is difficult to account for, unless it was adherent to the base of the skull, and yet we know that many of these midline endotheliomas take their origin from the falx. Except for this unusual immobility there appeared no obstacles to its removal, and in a more robust patient an attempt would have been made to mobilize it. After the operation it occurred to me that we might have attempted a subcapsular extirpation such as we practice at times in cerebellopontile angle tumors.

In this particular case, however, I doubt whether the patient would have survived any radical undertaking. The intolerance to surgical intervention of patients with tumors of long standing is an interesting speculative study. From the very beginning of an operation, the pulse, as in this case, becomes accelerated; a rate of 140 to 150 is common. The mere reflection of the osteoplastic flaps seemed a sufficient undertaking for one sitting and a two stage operation seemed imperative. At the second sitting, even before any attempt at demobilization of the 
tumor had been made, there was reason for anxiety. The disturbance of the cardiac mechanism in brain tumor cases I have attributed, rightly or wrongly, to a delicately balanced blood supply of the medullary centers. How else can one account for the rapidity of pulse rate and the falling of blood pressure? In the absence of serious hemorrhage there apparently is no other way of accounting for them.

CASE 5.-Summary: Successful extirpation of an endothelioma 3 by $2 \mathrm{~cm}$. from a patient whose illness began with fleeting attacks of aphasia, followed by jacksonian seizures; recovery.

History.-C. M., aged 17 years, was referred to the neurosurgical service at the University Hospital by Drs. William G. Spiller and H. M. Fussell. When 16 years of age, she first consulted one of us (Spiller) Sept. 21, 1918. About a year previously she suddenly lost the power of speech for about three minutes. while walking along the road. She was frightened. At first she stuttered and then was entirely unable to speak. There seems to have been no other symptom at this time. About a month later she again lost her speech suddenly, for about a minute and a half, without any premonition or stuttering, and again she had no other symptom. She tried to write while she was unable to speak this second time but could not form any letters during this period. She had lost her speech about six times in all for a brief period. About the middle of July, 1918, while in a field, objects suddenly seemed to be going around; she fell to the ground and was unconscious about ten minutes. About a month later, while riding horseback, she suddenly lost her speech; she got off the horse and laid down on the ground and may have lost consciousness. In the later attacks with loss of speech she had a peculiar sensation in her right forearm and hand, and she could not move the right hand at these times, but the hand twitched and the two times she lost consciousness the right side of the mouth twitched.

About three weeks before coming for examination her mother found her making a noise with her mouth, she was somewhat rigid, the right side of the mouth twitched and she was unconscious. In this attack there was a numb feeling in the whole right side, face, limbs and trunk. Dr. Zentmayer in September, 1918, found the veins of the left retina a little fuller than normal.

Attacks occurred which were observed by her parents. They began, the patient said, with a loss of voice, when she would lie down; a twitching of the right arm and the muscles around the mouth was noticed, which were drawn to the right side. In the early attacks she thinks the right leg moved but this is questionable. The attacks occurred about a week apart; the duration was the same, from one to three minutes, and they were characterized by twitching of the right arm and mouth muscles. Each attack began with what she felt was a loss of voice, which forewarned her so that she lay down. In the present month she had had two attacks and the beginning of a third, which apparently was abortive. In these attacks she had held the right hand firmly on her breast and the arm had not appeared to move, but the muscles of the mouth trembled and were drawn to the right. These last two or three attacks had not lasted for more than a minute or two and with less convulsive movements, the arm apparently not taking part.

Repeated examinations of the eyegrounds showed no positive change. Her muscular tone seemed as good as ever, there was not the slightest diminution of power in the right arm, and the grip of the right hand was perhaps unusually 
strong. Her general health and spirits, if anything, had been better this month than in the past two. She had as lively an interest in affairs as usual, was planning to return to school, and had been allowed to go to entertainments and take part in occasional dances as usual.

Preoperative diagnosis: Tumor of the motor cortex, left, near or in Broca's area.

Operation.-A craniotomy was performed by Dr. Frazier and his staff. Ether anesthesia was used. An osteoplastic flap was reflected, designed to expose the motor zone and the region of Broca. When the dural flap was reflected there was seen just above Broca's region an area of minute dimensions, less than a centimeter in diameter, that differed in appearance from the normal brain tissue. The nature of it at first was not realized, but on closer examination it proved to be a tumor which without difficulty was separated from its bed and removed. The tumor was quite the smallest of any in the experience of our clinic, measuring in its largest dimension not more than $3 \mathrm{~cm}$. The operation was free from any technical difficulties. The wound was closed without drainage.

Pathologic Diagnosis: Endothelioma.

Comment.-The attacks of loss of speech indicated a lesion of the left cerebral speech area, and they seem to have been purely of the motor type, as no sensory aphasia was noted. At first there was no other disturbance than that of motor speech and writing, and as the tumor was very small and could not have caused much pressure the loss of speech was a sharply defined focal symptom. It would seem to indicate a lesion of Broca's area. The loss of speech was complete temporarily, and this is the form of aphasia to be expected in a lesion of Broca's area. It is very different from that occurring with a small lesion of the sensory speech area. In this improper words are used, the patient cannot think of the words he wants to use and uses others incorrectly. This has been seen several times by one of us (Spiller) in tumor of the left temporal lobe. It is the earliest manifestation of beginning word deafness, and the improper use of words precedes distinct signs of word deafness. Indeed this improper use of words in the early stage of lesions of the left temporal lobe may be so slight that a search must be made for it. A patient now under observation from whom a large tumor of the left parietal lobe has been recently removed by Frazier understood everything said to him and spoke very well, but he at times could not think of the words he wanted to use, especially the names of objects, and showed beginning word blindness in that he confused figures and did not understand everything he read.

The loss of speech in this young girl was not caused by a temporary paralysis of the face center, as it does not appear likely that a temporary paralysis of all the muscles of speech could result from a lesion of the face center of one sicle. This probably would result only from a bilateral lesion of the center. The agraphia also is evidence of a true motor aphasia. 
Transitory motor aphasia with convulsive movements of the right side of the face and right upper limb later constituted the whole clinical picture. The father of the patient was a physician and understood the focal importance of these symptoms. Rather than permit his daughter to continue having these distressing attacks he consented to an operation, with the discovery of a minute well defined endothelioma in or very close to Broca's area, distinctly separated from the underlying brain, and its successful and complete removal. Soon after the operation all convulsions ceased and no more have occurred. The recovery is complete in every detail and there seems to be no probability of recurrence. Not a single symptom persists.

The occurrence of complete transitory motor aphasia in a young person may therefore be a focal symptom of importance. In an elderly person it may result from arteriosclerosis, paresis or some other cause.

A case very similar to this one, except in regard to the aphasia, is reported by Pönitz. ${ }^{7}$ Aside from some hysterical manifestation, the important symptom was clonic convulsion of the left side of the face, except the upper part of the face, occurring in attacks, of two years' duration. Later the left upper limb became involved in the convulsions. A solitary tubercle the size of a cherry stone was found in the right facial center.

CASE 6.-Summary: The successful removal of a tumor, with the characteristics of a fibroma, from the right cerebellar fossa. The patient recovered and continues free from symptoms three years after the operation.

History.-Mrs. O., aged 45 years, was referred to the neurosurgical service of the University Hospital by Dr. G. A. Young of Omaha, to whom I'am indebted for the following history:

Four years ago the patient began to complain of dizziness and unsteadiness of gait; the latter was slight at first but gradually became more pronounced, and it was constant. The dizziness was not associated with rotation of object or self. Eighteen months ago she began to complain of headache and vomiting periodically. Some months later she experienced a sense of numbness in the right side of her face.

At the present time there is a definite hypesthesia with loss of the conjunctival reflex. There is a slight weakness of the right facial distribution but no disturbance in either of the cochlear or vestibular branches of the auditory nerve. The visual fields are slightly contracted and there is an elevation of two diopters in each disk. There is no disturbance of the motion or sensation in any of the four extremities, and the reflexes are normal. There is a suggestion of adiadokokinesis in each upper extremity. She speaks of her left side as being her good side, without being able to say precisely in what way it is the better. At the present time she has comparatively no headache, but nausea and occasional vomiting persist.

7. Pönitz: Deutsch. Ztschr. f. Nervenh. 67: Nos. I and 2, p. 89. 
At the present time the Bárány tests show an irregular spontaneous past pointing in both arms which may be either to the right or left; both vertical and horizontal canals react to the caloric test in both right and left ears. In the turning test she shows a normal nystagmus reaction in either direction, the past pointing is somewhat indefinite, but she past points in the right direction when turned to both left and right. The falling reaction is normal also to the right and left. The subjective sense of after-turning vertigo has a duration of about twenty seconds when turned to both right and left.

Preoperative Diagnosis: Tumor of the right cerebellar chamber.

Operation.-A suboccipital craniotomy was performed by Dr. Frazier and his staff. An encapsulated tumor was found and removed from the right cerebellar fossa.

Pathologic Diagnosis : Fibroma.

Unfortunately the record of the physical examination and the operative details have been lost, so that we are able to present only the foregoing facts. The patient recovered and is entirely well, three years after the operation.

CASE 7.-Summary: Seven years after the onset of symptoms and one year after a suboccipital decompression, extirpation of glioma from left cerebellar fossa; three courses of radium therapy before operation, during which tumor became encapsulated. Three years after extirpation of growth no evidence of recurrence.

History.-E. E. S., aged 38 years, was referred to me by Dr. Charles F. Neu of Indianapolis. The family, social and previous history were without interest.

Six years ago the patient's wife observed that his gait was shuffling, but no other symptom was noticed until three years later when the hearing of his right ear became impaired. Two and a half years ago he noticed numbness in his lips at the angle of the mouth, and an abrasion on the tongue which he had bitten unknowingly. About the same time the hearing of the left ear became impaired and sensation in the left side of his face was lost. In walking he staggered to left and occasionally lost his balance and fell. His eyesight was not as good as it had been and headaches became more or less constant. During the preceding eighteen months he had attacks of vomiting and, because of his disability, had to give up his position as a school teacher. Within the year and before he came under our observation, a suboccipital decompression was performed. This relieved his headaches in part, but the patient thought his incoordination was more marked. Recently he had had difficulty in talking and swallowing, occasionally choking when swallowing liquids.

Physical Examination.-Head: There was a moderate hernia at the site of the previous decompression.

Cranial Nerves: Second, Third, Fourth and Fifth Nerves: The pupils reacted to light and accommodation. Ocular rotations were full. The vision in the right eye was $6 / 12$; the papilledema plus 5 diopters. Vision in the left eye was $6 / 15$; papilledema plus 6 diopters. The disk was rather spread out and more succulent than one would expect in a choking of long standing. It may imply an acute exacerbation (Holloway). The fields showed some irregular contraction but nothing of localizing significance. There was horizontal nystagmus on lateral rotations; on upward and downward rotation the movements became vertical. Fifth Nerve: There was a sense of numbness in the left trigeminal distribution. Seventh Nerve: The upper branches were slightly involved. Eighth Nerve: There was marked impairment of hearing in the left 
ear. There was vertigo on stimulation, with complete absence of past pointing of the left arm to the left. Impaired response from the right or functioning ear was noted. The right labyrinth was not affected. The findings suggested a lesion of the left cerebellopontile angle with extension to the left cerebellar hemisphere and brain stem. Ninth Nerve: There was difficulty in swallowing. Twelfth Nerve: There was no deviation of the tongue when protruded.

Extremities: The grip of both hands was firm and equal. No weakness was present in the lower extremities.

Reflexes: Biceps, triceps and patellar tendon reflexes were more marked on the left than on the right side.

Coordination: Movements of the left arm and leg showed marked incoordination. Adiadokokinesis was marked.

Miscellaneous: The blood pressure was: systolic 135 ; diastolic 70 . The red blood cells numbered 2,510,000; the white blood cells, 8,240; hemoglobin 92 per cent. The urinalysis was negative. Roentgenogram: The posterior clinoid processes were exceedingly thin. The sella turcica was not enlarged. The right and left internal auditory meatus were of equal dimensions.

Preoperative Diagnosis: Tumor of the left cerebellopontile angle.

Operations.-A suboccipital craniotomy was performed by Dr. Frazier and his staff. Ether anesthesia was used, endopharyngeal. On reflection of the flaps a tumor was exposed occupying the entire left fossa. It had the gross appearance of a glioma and contained a large cyst. Extirpation was considered impossible and $50 \mathrm{mg}$. of radium were inserted into the cavity of a cyst to be removed in eighteen hours. The wound was closed.

Before the patient was discharged, radium was applied by Dr. Pancoast over the surface in the suboccipital region. Three months after the operation the patient returned for observation and a second course of radium therapy. His sight, hearing and articulation were improved. Incoordination was about the same. There was a marked subsidience of the choked disk and the nerve margins were readily discernible. Elevation of the right disk was plus 2 diopters; of the left plus 3 diopters.

Eight months after operation a third course of radium therapy was given. He was totally deaf in the left ear but hearing in the right ear was much improved. There was no particular change in the condition noted except in the movement of the left leg and vision. The heel to knee test (left) revealed no ataxia. Vision in the right eye was $6 / 9$; in the left $6 / 9$ (previous to operation it was $6 / 20-6 / 15$ ). The fundi level on either side was plus 1 diopter. The disks were somewhat obscured on the nasal side but were visible in the temporal margins.

Ten months after operation, the patient returned with evident aggravation of symptoms, particularly noticeable in the three previous weeks. Headache had returned, hearing in the right ear again becoming impaired; lately he had been swaying to the right in walking, previously only to the left. His vision was not as good; it was $4 / 15$ in each eye, the disks were plus 4.5 diopters. In other respects there had been no appreciable alteration in the clinical picture. Because of the evident recurrence and at the patient's earnest request a second operation was agreed on.

Operation 2.-A suboccipital exploration was made. When the musculoaponeurotic flap was reflected, the dura not having been replaced at the previous occipital decompression, the tumor presented itself. But in appearance it differed in that now it was well encapsulated. Complete extracapsular extirpation did 
not seem feasibie; the capsule was split and the contents removed. Grossly the tumor had the appearance of a cystic glioma. Again $50 \mathrm{mg}$. of radium were introduced within the capsule, to be removed in eighteen hours. Wound closure was made.

Pathologic Diagnosis: Glioma.

Final Note.-Three years after tumor extirpation and nine years after the appearance of the first symptom, the patient returned for examination. He reported that he had been active in business, and had less difficulty in walking; the hearing in the right ear was much more acute, and he had had no natsea,

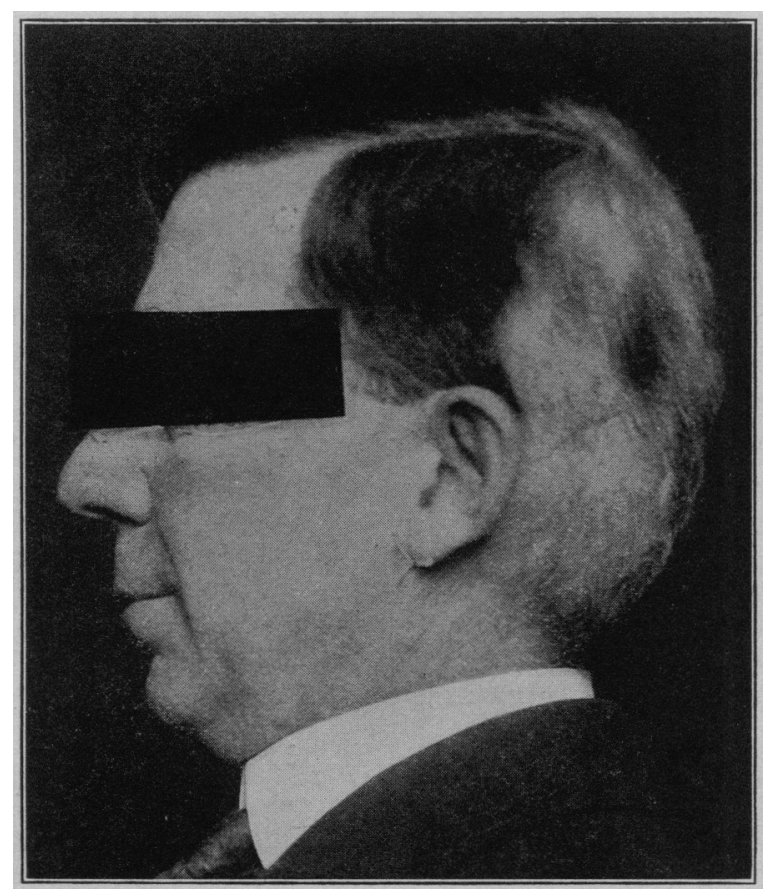

Fig. 5.- Photograph of patient taken nine years after operation. In the area to which radium was applied the hair is white.

vomiting or headache. On examination there was ataxia and dysmetria in the left upper and lower extremity; the nystagmus, particularly in extreme positions, persisted. Vision in the right eye was $6 / 9$ plus 2 , in the left $6 / 12$ plus 2. The margins of the disks were clear; no papilledema.

Résumé of Case.-Nine years ago, the first symptom, disturbance of the gait. appeared. Six years ago there was disturbance of hearing followed by numbness of the face, failure of vision, vomiting, headache, difficulty in swallowing and speech, dysmetria, etc. Four years ago at a suboccipital decompression the tumor was exposed but not removed; radium therapy. Three and one half years ago radium therapy (course 2) was utilized. Three and one quarter years ago a third course of radium therapy was given. Three years ago extirpation of the growth was performed and a fourth course of radium therapy was given. At present there is no evidence of recurrence. 
Comment.-The larger one's experience with tumors of the brain the more one is struck with their rate of growth. How slow it is compared to malignant tumors elsewhere. Even is this so, as in the case under discussion, with gliomas which in their cellular characteristics resemble the sarcoma group. In this case there were signs of a tumor developing six years before the operation, and though radical extirpation was not possible in the surgical sense, there has been no evidence of recurrence three years after removal.

The localization of the growth was not difficult. In the evolution of the clinical picture the first symptom was disturbance of gait and some time elapsed before there was any other evidence of tumor. The three year interval between the initial symptom and impairment of hearing was more than suggestive of a lesion originating in the cerebellar hemisphere rather than the cerebellopontile angle. At least this interval excluded the likelihood of an acoustic tumor. As a matter of fact, there was never complete nerve deafness. One of the earlier symptoms was a sense of numbness in the face, on the affected side, and yet at no examination could one demonstrate any loss of appreciation of tactile or pain sense.

What may have been the effect of radium therapy on the tumor growth is a matter of speculation. At the second operation there was a definite encapsulation of the growth, not observed when the tumor was originally exposed at the decompressive operation a year before. That radium incites hyperplasia of connective tissue elements is generally acknowledged, but this would hardly explain the formation of a capsule about the tumor, and connective tissue elements within a glioma are negligible. From what we know of the effects of radium on tumors, we have come to the conclusion that it is more effective in the endotheliomas than in the gliomas.

When an entire cerebellar hemisphere has been destroyed by the tumor one cannot of course expect recovery of function after the tumor is removed. .There must persist, as in this case, disturbance of the function, attributable to the hemisphere destroyed. And so while the headache, vomiting, papilledema and to some extent the deafness disappeared (all pressure phenomena), the ataxia, dysmetria, disturbance of equilibrium and gait persisted.

As to the operability of gliomas, in many instances they have been regarded by us as inoperable, particularly diffuse subcortical infiltrating growths of the cerebral hemisphere. But in this case the tumor occupied the entire left cerebellar fossa; one could not see a vestige of the cerebellar hemisphere, and as it appeared well encapsulated the contents of the capsule at least could be extirpated. Even should there be a recurrence at some later date, a second operation should be advised with a reasonable hope of removing the recurrent growth. 
Prolongation of life, even after partial extirpation, should be given a prominent place when discussing the pros and cons of surgical interference in brain tumors. To be able to prolong the patient's life, in a reasonable state of health and activity and at the same time to conserve vision, is in itself a sufficient endorsement of surgical intervention. In this case the patient has had over three years of complete comfort and business activities.

CASE 8.-Summary: A man, 29 years of age, with a fibroma of the acoustic nerve, accurately localized before operation, subsequently exposed and removed; recovery.

History.-L. A. S., aged 29 years, was referred to the neurosurgical service by Dr. William G. Spiller with the following history:

Three years ago the patient noticed that he did not hear well with his right ear; and ten months ago his hearing, he observed, had become much worse. Seventeen months ago, when he became tired and nervous he began to have a "roaring" in the right ear. He noticed a peculiar sensation in his gums and cheek on the right side, twenty months ago and fourteen months ago difficulty in writing and shaving. Nothing of consequence developed for almost a year when (five months ago) he began to have trouble in walking, with a tendency to stagger, usually to the right, when walking in the dark or on a narrow path. A month later he first complained of disturbance of vision; he could not focus accurately, particularly when moving about. Objects looked blurred, but there was no dizziness. Now, when reaching for an object his hand miscalculates the distance by an inch or so and in going upstairs he has to concentrate on the movements of his right foot.

The chronologic sequence of events is: Three years ago, there was disturbance of hearing (right); twenty-two months ago, deafness more pronounced (right); twenty months ago, sensory disturbances of gum and cheek (right); seventeen months ago, tinnitus in right ear; fourteen months ago, awkwardness in movements of right hand; four months ago, staggering in walking; three months ago, visual disturbances; at present, awkwardness in movements of the right hand and right foot.

Physical Examination.-Cranial Nerves: The first, third, fourth, sixth, tenth and eleventh nerves were normal. There were no ocular palsies. Nystagmus was present when looking to the right or upward (ophthalmic report). Fifth Nerve: The sensation in his face differed on the two sides. When he was pricked with a pin in the distribution of the fifth nerve he felt it as a sharp prick on the left side, but on the right side he said it felt "muffled," though he knew it was sharp, not dull. The sensation was the same on the two sides in the cervical distribution in the lower part of the face. When he chewed he used the left side because he said the right cheek and gums felt as if they had been burned. The right eyeball and cornea when touched with the head of a pin showed no contraction of the lids; the left conjunctival reflex was normal. When he bit, there was no difference in the masseter or temporal contractions on the two sides.

Seventh Nerve: When he wrinkled his forehead the lines were not quite as deep at the extreme right as on the left side, and there was a gradual lowering of the eyebrow on that side so that in order to keep his forehead 
wrinkled he had to make repeated efforts, but this was slight. When he showed his teeth both corners of his mouth were drawn back equally, but soon the right side began to relax, and there was a twitching of the muscles in an effort to keep the corner drawn up. The resistance to raising the upper lid when the eye was closed was slightly less in the right eye (Dr. B. A. Randall).

Eighth Nerve: The right ear seemed deaf for all lower tones and even the higher ones were less well heard than on the left. The left ear responded normally to all tests. Past pointing was not spontaneously present, but easily though briefly elicited by rotation or touch. There would seem to be some brainstem lesion anterior to the cerebellar peduncles. The absence of ocular evidence suggested a very small lesion. He could not hear a watch tick close to or even on his right ear. The hearing in his left ear was apparently normal.

Ninth Nerve: The soft palate was normal.

Twelfth Nerve: There was no deviation in the protruded tongue.

Sensation: In the upper extremities, sensation was normal for touch and pain. There was no asterognosis and no loss of sense of position. In the lower extremities there was no loss of sense of position and no disturbance of sensation.

Reflexes: In the upper extremities the reflexes were equal and normal. In the lower extremities the Achilles tendon reflexes were prompt and equal. The right patellar reflex was a trifle prompter than the left. There was no Babinski sign.

Cerebellar Disturbances: There was slight but distinct dysmetria and adiadokokinesis in the right hand. When he wrote he did not slide his right hand along the paper (dyssynergia).

Gait: With his eyes open the gait and station were normal; with eyes closed, the station was good but in walking there was a tendency toward deviation to one side or the other.

Roentgenogram: There was no evidence of any sella deformation. In all respects negative.

The Wassermann reaction of the blood was a doubtful negative. The cerebrospinal fluid was negative.

Résumé of Symptoms: The symptoms were: deafness in the right ear, tinnitus in the right ear, hypesthesia in the right trigeminal zone, facial paralysis partial (right), retinal veins a little larger than normal, dysmetria of the right upper extremity, dyssynergia of the right upper extremity, adiadokokinesis of the right upper extremity, patella reflex a trifle prompter on the right side and deviation to the right in walking.

Preoperative Diagnosis: Acoustic tumor.

Operation.-Ether anesthesia was used, endopharyngeal method. A suboccipital craniectomy was performed with extirpation of the tumor. The bone was removed from over both cerebellar hemispheres, the occipital sinus ligated and the dural flap reflected. There was an increased intracranial pressure, but when the fluid in the basal cistern escaped, the pressure was restored to within normal limits. Displacement of the right cerebellar hemisphere disclosed an acoustic tumor about the size of a grape. The tumor was bisected and removed in segments. Hemorrhage from two points was controlled with muscle grafts. Closure was made without drainage.

At the conclusion of the operation 600 c.c. of citrated blood was transfused.

Postoperative Course.-The patient's convalescence was somewhat prolonged. $\mathrm{He}$ was extremely apprehensive throughout. For a long while he complained 
of difficulty in swallowing and would not take solid food, although he never choked when taking liquid food as one observes when there is any disturbance of the muscles of deglutition. He complained also for some time of mucus collecting in the throat. But apart from these symptoms there were no unusual complications.

Pathologic Report.-The tumor consisted of spindle-shaped cells having a parallel arrangement and forming bundles. The tumor contained a fair amount of connective tissue and some round nuclei, which were perhaps in part at least transverse sections of spindle-shaped nuclei. The tumor was a typical fibroma (Dr. W. G. Spiller), the characteristic tumor of the acoustic nerve.

Comment.-The sequence of events in the early history were characteristic of an acoustic tumor. Of significance in the diagnosis was the initial deafness. Three years before the operation the patient noticed that he was becoming deaf and for many months this was the only symptom. Then followed in sequence the involvement of the sensory root (hypesthesia), tinnitus and the involvement of the facial nerve. After that there were evidences of disturbance of cerebellar function, dysmetria, dyssynergia, adiadokokinesis and staggering. The primal disturbance of hearing, antedating by so many months any other symptom, either of the cranial nerves or of the cerebellum, was of great significance in the differentiation of angle tumors, other than those originating in the acoustic nerve or of tumors of the cerebellum with secondary invasion of the cranial nerves.

$U_{p}$ to the time of operation there had been no obstruction to the outlet of the ventricles, hence the absence of pressure phenomena. Apart from a slight fulness of the retinal veins there were none. The absence of ventricular distention was observed at the operation, since once the fluid in the posterior fossa escaped there was no evidence of pressure, and it was not necessary, therefore, as in many explorations, to evacuate the ventricles. The right hemisphere was displaced without any difficulty sufficiently for the manipulations necessary for the removal of the tumor.

The tumor, as reported, was a fibroma and not as in many instances an endothelioma. But even though it was a fibroma, there is a possibility of recurrence. These two tumors, fibroma and endothelioma, have similar characteristics; each is relatively benign, but each may recur. An endothelioma may recur as a diffuse process and a fibroma may become readily a spindle cell sarcoma (Spiller).

The surgical problem was devoid of any technical difficulties. The accuracy of localization and the character of the tumor rendered the exposure of the growth and its removal a relatively simple procedure.

The resort to blood transfusion after prolonged intracranial procedures, particularly after stboccipital operations, we believe has merit. 
It has not been our practice to reserve transfusions for those cases in which hemorrhage has been profuse. This in itself constitutes a positive indication. But when there has been a prolonged anesthesia and a prolonged operative siege we find that the reaction from these after transfusion is prompter, and the convalescence shortened. From the condition of the patient the day after the operation, when transfusion has been practiced, one would not suspect that he had been subjected to a protracted ordeal on the operating table the day before. The value of blood transfusion in this particular field is enthusiastically recognized by all who come in contact with the patient.

\section{ABSTRACT OF DISCUSSION}

Dr. Charles K. Mills of Philadelphia said that, with regard to very smal! growths, he had had several experiences, one of the growths being in Broca's area and another in the parietal region. The paper was instructive in that it supported the older so-called classic view of aphasia as against the hypotheses of Marie. With regard to epilepsia continua, Dr. Mills said that he had had several cases, for one of which he had had a cranial-cerebral operation over the motor area performed by Dr. Frazier. No lesion was revealed. Dr. Mills said he recalled that Dr. Burr had, some years ago, reported a case of epilepsia continua and discussed the subject in a paper. Of course the whole subject belongs to the old and interesting field of accurate cerebral localization.

Dr. Mills remembered quite clearly the case to which Dr. Spiller alluded, in which they had made the diagnosis of a lesion in the facial cortical center, necropsy showing that the lesion was in the cerebellopontile angle. Recurring facial spasm of moderate intensity was a striking feature in this case. The spreading of jacksonian limb symptoms in these cases of cerebellar pontile lesions was, Dr. Mills thought, not difficult to explain, owing to the proximity of the pyramidal tracts.

Dr. H. H. Hoppe of Cincinnati said, in connection with the small tumors of the psychomotor area, that it might be interesting to know that at times they are tubercles, which are arrested in their growth, become calcified and may remain latent for many years.

A patient was brought into the Cincinnati General Hospital with a supposed stroke of apoplexy on the right side, sudden in onset. He died without regaining consciousness. Necropsy revealed a calcified mass, about the size and shape of a peanut, just below the cortex of the rolandic area in the ascending frontal convolution on the left side. The history of the case, obtained from a relative, disclosed that forty years before, the patient, when 16 years of age, had developed gradually, in the course of several months, a right-sided weakness of the body. He recovered from this and for forty years afterward did hard manual labor.

The pathologic examination revealed that the mass was a calcified tubercle surrounded by a cartilaginous envelope.

Dr. Hugh T. Patrick of Chicago mentioned a case of epilepsia partialis continua, in a boy of about 10 years. The first symptom had been intermittent shaking of the right foot. In other words, it continued uninterruptedly for a while and then stopped for a time. The movement very much resembled that of some of the shakers with war neuroses. Another feature of it was that it 
continued during sleep. When Dr. Patrick saw the boy he was sound asleep but the right leg was in this continuous clonic spasm. By that time the boy had also developed typical jacksonian fits, beginning in the right leg. The shaking was interrupted by a more tonic spasm, succeeded by a clonic spasm that spread over the entire right side. It was a case of cortical tumor of the left hemisphere.

Dr. William G. Spiller of Philadelphia said he was aware of the paper written by Dr. Burr, which was published some years after the one by Dr. Martin and himself, and a reference was made in the paper by Dr. Frazier and himself to Dr. Burr's paper. 